Session Number 2793

\title{
Technology Enhanced Laboratory Manual for Introduction to Environmental Engineering
}

\author{
L.R. Chevalier, J.N. Craddock, C. Vallath and A. Arndt \\ Dept. of Civil Engineering/Interractive Multimedia Program \\ Southern Illinois University Carbondale \\ Carbondale, IL 62901-6603 \\ PH: 618-453-6648 FAX: 618-453-3044 \\ cheval@engr.siu.edu, craddock@ce.siu.edu \\ cvallath@yahoo.com, arndtae@yahoo.com
}

\begin{abstract}
The main objective of the lab manual is to provide an on-line or CD-ROM based reference for conducting experiments in support of an introductory course in environmental engineering. Unlike printed manuals, this laboratory manual, or labware, can provide technology-enhanced tools to enrich the learning environment and experience. These features provide a valuable tool for a wide range of campus environments. The manual can be adapted by two- or four-year programs, and utilized with or without expensive laboratory equipment. The laboratory descriptions include detailed photography of equipment, as well as quality video and sound clips of the experiments and their application. In addition, multiple sets of data are included with each experiment. These data sets can be used in lieu of performing the actual experiment, as additional examples, or for statistical analysis. This paper also presents two unique interactive modules incorporated into the labware. The first module illustrates the concept of lake stratification and lake turnover incorporating data obtained from the Campus Lake at Southern Illinois University. The second module illustrates some concepts from a noise pollution experiment developed for the class. Both cases include a detailed description of the development of the modules. The work is supported in part from a grant from the National Science Foundation, the College of Engineering at Southern Illinois University Carbondale and the College of Mass Communications and Media Arts at Southern Illinois University Carbondale.
\end{abstract}

\section{Introduction}

The work presented in this paper is part of a project developing multimedia laboratory courseware (labware) for Civil and Environmental Engineering curricula. In particular, we are developing labware for the environmental engineering and strength of materials laboratory. This paper will focus on two of the multimedia components of the environmental engineering laboratory in addition to presenting an overall view of our pedagogical approach. At this stage, we are still in the formative development of the project, having just started external reviews in academia and indus try. The project is a joint effort between the Department of Civil Engineering

"Proceedings of the 2002 American Society for Engineering Education Annual Conference \& Exposition Copyright? 2002, American Society for Engineering Education" 
(College of Engineering) and the Interactive Multimedia Master's Program (College of Mass Communication and Media Arts). As a result of this collaboration, the project has elements of design and multimedia that is generally not associated with laboratory manuals developed for the civil and environmental engineering curricula.

Multimedia applications represent the best application of modern technology to education and training in all areas. It can be very cost effective and increase retention rates dramatically [1]. Computer technology and multimedia applications are particularly relevant in engineering education [2- 3]. They give students the opportunity for self-paced learning in an interactive environment [4]. The format is nonlinear, allowing the student to review certain parts in a manner that is much easier than with simple videotapes or audiocassettes. The effectiveness of computer-based instruction has been widely documented in numerous studies. These results are summarized in three survey papers [5 - 7]. Web-based classes have been also proven to be effective allowing class time to be spent in other ways [8 - 9]. Multimedia instructional modules tend to engage students in active learning [10 - 11], which is very important in modern educational theory [12].

The labware is intended to enhance student learning through the development of and exposure to richer learning tools, resources, and advanced technologies. The pedagogy promoted by our approach is to engage students in active learning, while concurrently accommodating various leaning styles. By developing multimedia labware for the course, which students can access at any time, we can strengthen the bridge between application and classroom theory.

To accomplish this, the labware combines text, illustrations, photographs, video-clips, sound, simulations, animations, hypertext descriptions, and hot-links to the Internet, making it truly multi-media. The labware is designed to present applications, elements of theory, experimental procedure, data collection, data reduction, report writing and statistics.

The labware has potential use in a diverse range of university environments. For laboratories equipped with the appropriate equipment, the labware can be used with the expectation that students review various aspects of the $\mathrm{CD}$ at different stages of the learning process. Additional data sets can be accessed to expand the experiment to different materials or for statistical analysis. For laboratories that do not have access to state-of-the-art equipment, the students can still investigate and link the theory, experimental methods, and data collection in a "virtual lab" environment with the same benefit of accessing the information through different stages of the learning process.

\section{Environmental Engineering Labware}

The Introduction to Environmental course is a junior level Civil Engineering course required for all civil engineering majors. In addition, students from the environmental studies program may take this course. The laboratory component of the course includes, but is not limited to, measuring biochemical oxygen demand, determining solids content, measuring the temperature profiles in a lake, and conducting coliform bacteria tests. At this stage, the individual laboratories have the common elements of an introduction, materials, procedure, specific report requirements, data sheets and references. A number of the laboratories also have additional data

"Proceedings of the 2002 American Society for Engineering Education Annual Conference \& Exposition Copyright? 2002, American Society for Engineering Education” 
sets and video clips detailing the application of the laboratory in civil and environmental engineering as well as detailing the experimental procedure. We are now at the stage of integrating interactive components. In particular, this paper will present the development of 1) a module illustrating seasonal changes in a lake's temperature and dissolved oxygen profile and 2) a module within the noise pollution laboratory demonstrating frequencies.

\section{Lake Profile Laboratory}

In this laboratory, students measure the temperature and dissolved oxygen concentration of water as a function of depth in a lake. At Southern Illinois University Carbondale, we have a 40-acre lake on campus. Campus Lake (originally called Thompson Lake) has an average depth of eight feet, with the deepest part reaching fifteen feet. It was constructed in 1880 to serve as a local ice supply. It was later used for swimming and fishing by a private club. Southern Illinois University (SIU) entered into a lease agreement with Lavina Thompson on April 8, 1930, and eventually purchased the lake in 1946. Each semester, students take boats to the deepest part of the lake and use probes to measure temperature and dissolved oxygen concentration profiles. Included in the labware are numerous data sets that can be used by students studying water quality. During the fall, shorter days and colder temperature cause lakes to turnover. The data in fact, shows this phenomenon.

\section{- Lake Profiler}

$-\square \times$

Dissolved Oxygen Profile For July 24
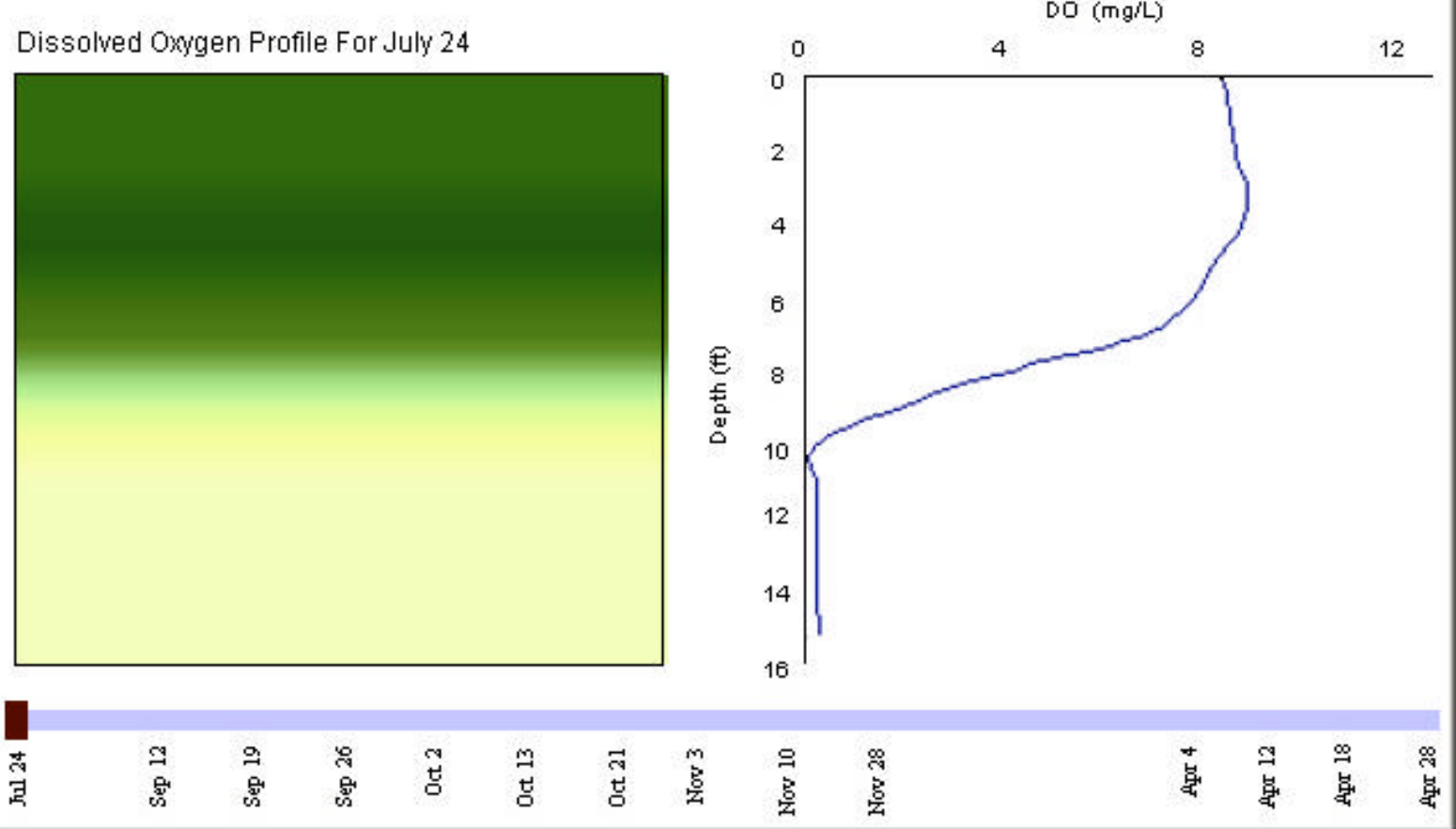

- Dissolved oxyen OTemperature

Figure 1: Opening screen for the interactive program Lake Profiler.

"Proceedings of the 2002 American Society for Engineering Education Annual Conference \& Exposition Copyright? 2002, American Society for Engineering Education” 
The interactive program, Lake Profiler, was developed to graphically depict depth-dependent changes in temperature (T) and dissolved oxygen (DO) content in Campus Lake at different times of the year. The criteria applied to the design of this program was that it had to be intuitive enough to use without written directions and flexible enough to accommodate a wealth of data within a single screen, yet remain small enough to allow a reasonable download time over the Internet.

Lake Profiler has two components has been developed from this data, one showing the dissolved oxygen concentration changing over time, the other showing similar changes in temperature.

Figure 1 shows the first screen when entering the program. The first box shows the difference in dissolved oxygen concentration through a vertical color gradation representing varying values of dissolved oxygen concentration. The graph to the right provides numerical values for the profile throughout the depth of the lake. The user can move the black box slider above July 24 to other dates to see how the concentration changes

The program is designed so that functional features are common whether the user chooses to view a temperature or a dissolved oxygen profiles. To view the temperature profile, the user simply selects the ' $\mathrm{T}$ ' radio button. Figure two shows how the temperature varies in April.
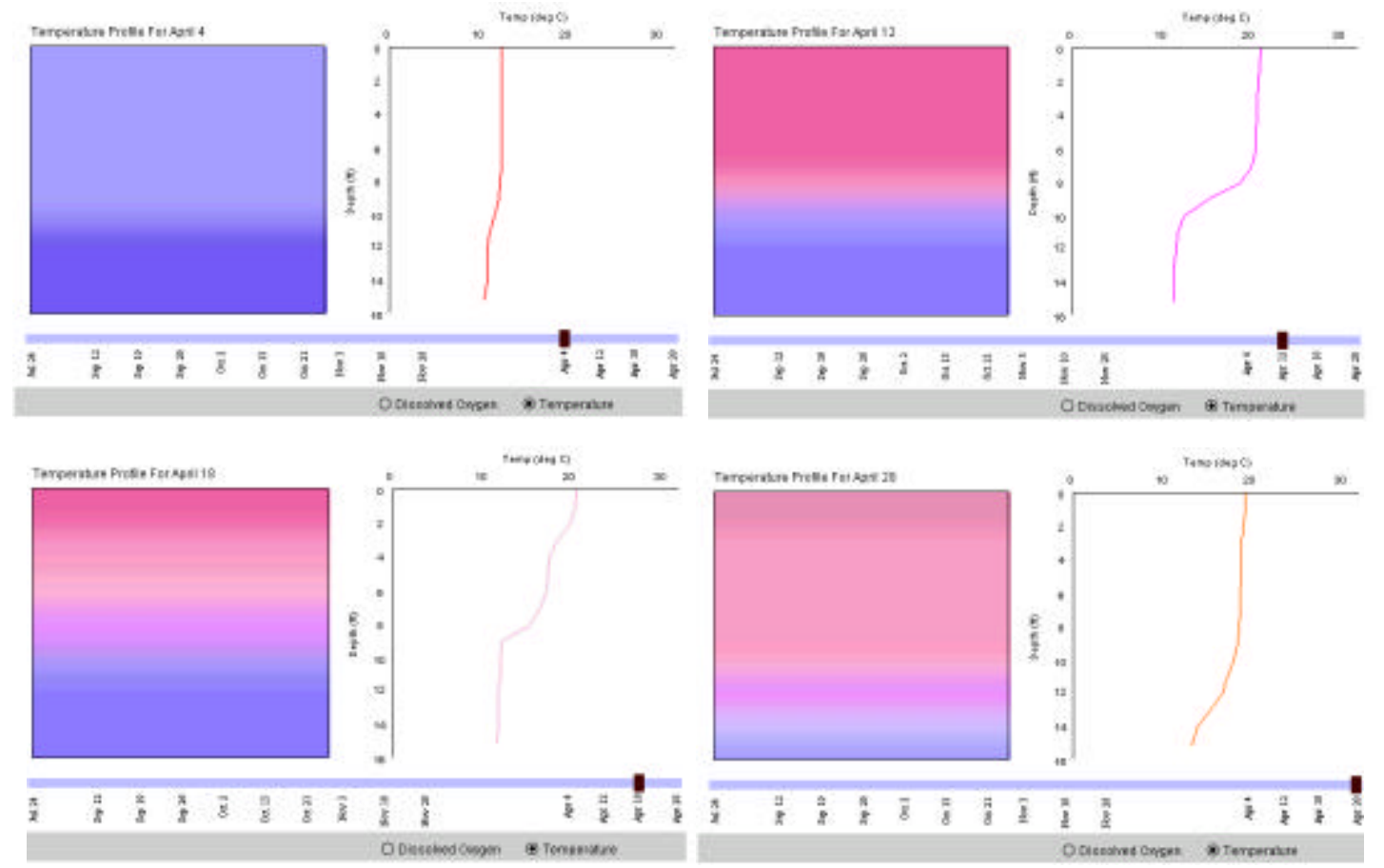

Figure 2: Temperature profiles in series of a lake as shown in the module Lake Profiler.

Lake Profiler was developed using Macromedia Director 7.0 for Windows and converted to a Shockwave application for distribution over the Internet. The individual graphs and shaded cross-sections of the lake were developed as bitmaps and imported into the cast of the Director projector. Although it may be possible to develop algorithms for graphing and for coloring in gradients on the fly based on numerical values, the use of bitmaps allowed the program to be

"Proceedings of the 2002 American Society for Engineering Education Annual Conference \& Exposition Copyright? 2002, American Society for Engineering Education” 
developed quickly. Despite the large number of bitmaps, the file size of the Shockwave application is less than $1 \mathrm{MB}$.

Noise Laboratory

The overall objective of the noise pollution laboratory is to have students measure sound levels from various sources and comparing this measured data to simplified models. However, to understand the basic concepts of sound, we have included an interactive module to illustrate how different notes on the piano produce different frequencies. In this module, a student can hear notes over an octave, and relate these notes to their frequencies.

The interactive keyboard module was created using three software programs; Macromedia Dreamweaver, Adobe PhotoShop and ProTools. The main image of the keyboard and the frequency numbers were created and edited in Photoshop. The images were optimized as .gif files. The sounds of the notes on the piano were recorded directly to a Macintosh G4 computer using a synthesizer fed into the computer through an audio board. The software ProTools was used to record, edit and compress the audio. The final output for the audio was a .wav file.

The separate image and audio files were brought together and put into HTML format using Dreamweaver. The image has image-mapped areas to designate the keys for users to click using their mouse. When the image-mapped area for a key is clicked the image of the frequency that corresponds to that key is displayed as .wav file for the note plays.

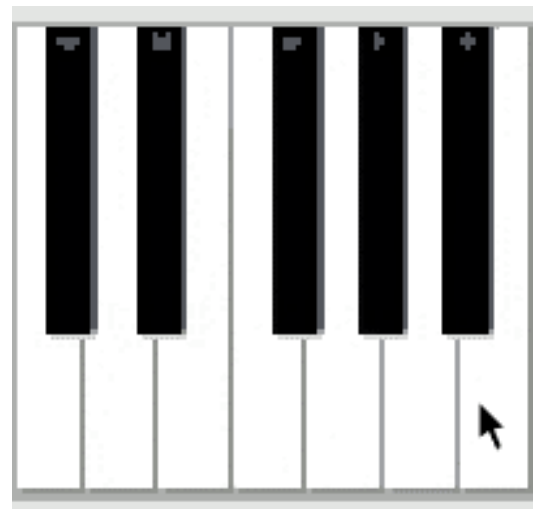

\section{$493.883 \mathrm{~Hz}$}

Figure 3: Piano keyboard module.

\section{Conclusion}

This project is still in the formative stage. The final product will be published on a CD-ROM, with portions of the material available on the World Wide Web. At this time it can be accessed at: 
http://civil.engr.siu.edu/nsflab/

Several papers outlining the development and formative assessment of the project are also available for further information [13-18].

\section{Acknowledgement}

This project is funded in part from the National Science Foundation (DUE CCLI Project Number 9952577), the College of Engineering at Southern Illinois University Carbondale (SIUC), the Department of Civil Engineering at SIUC, the Materials Technology Department and the College of Mass Communication and Media Arts at SIUC.

\section{Bibliography}

1. Iskander, M.F., Catten, J.C., Jones, A., Jameson, R., and Balcells, A., "Interactive Multimedia Lessons for Education," 1996 American Society for Engineering Education Annual Conference Proceedings.

2. Green, R.A., and Huddleston, D.H., "Changing the Engineering Undergraduate Experience by Appropriate Use of Computer Technology," 1998 ASEE/IEEE Frontiers in Education Conference.

3. Chin, R.A., and Frank, A.R., "The Multimedia Instruction Initiative: Implications for Engineering Education," 1996 American Society for Engineering Education Annual Conference Proceedings.

4. Griffith, M.L., Lamancusa, J.S., Engel, R., Jorgensen, J.E., and Valdez, J., "Multimedia Courseware to Enhance the Classroom Experience," 1997 ASEE/IEEE Frontiers in Education Conference.

5. Niemicec, R., and Walberg, H., "Comparative Effects of Computer-Assisted Instruction: A Synthesis of Reviews," Journal of Educational Research, Vol. 3 (1), 1987, pp 19-37.

6. Kulik C-L., and Kulik, J., "Effectiveness of Computer-Based Instruction: An Updated Analysis," Computers in Human Behavior, Vol. 7, 1991, pp 19-37.

7. Kadiyala, M., and Crynes, B.L., "Where's the Proof? A Review of the Literature on Effectiveness of Information Technology in Education," 1998 ASEE/IEEE Frontiers in Education Conference

8. Wallace, D. R., and Muttoni, P., "A Comparative Evaluation of World Wide Web-Based and Classroom Teaching," Journal of Engineering Education, July, 1997, pp 211 - 219.

9. Wallace, D.R., and Weiner, S.T., "How Might Classroom Time Be Used Given WWW-Based Lectures," Journal of Engineering Education, July, 1998, pp 237 - 248.

10. Richards, L.G., Gorman, M., Scherer, W.T., and Landel, R.D., "Promoting Active Learning with Cases and Instructional Modules," Journal of Engineering Education, October, 1995, pp 375 - 381.

11. Azemi,A., "Developing an Active Learning Environment with Courseware Approach," 1998 ASEE/IEEE Frontiers in Education Conference.

12. Meyers, C., and Jones, T.B., Promoting Active Learning, Jossey-Bass Publishers, 1993.

13. Craddock, J.N, Chevalier, L.R. and Musumhi, K., 2002. Mechanics of Materials Interactive Multimedia Labware. Proceedings of 2002 American Society for Engineering Education Annual Conference, Montreal, Canada.

14. Chevalier, L.R., and Craddock, J.N, 2001. Formative Assessment of Interactive Multimedia Labware for Environmental Engineering Laboratory. International Conference on Engineering Education, Aug. 6-10, 2001, Oslo/Bergen Norway.

15. Chevalier, L.R. and Craddock, J.N., 2001. Interactive Multimedia Labware For Civil Engineering Curricula. 2001 ASEE Annual Conference, June 24-27, 2001, Albuquerque, New Mexico.

16. Craddock, J.N. and Chevalier, L.R., 2000. Interactive Multimedia Labware for Torsion Experiment, Proceedings ASEE Conference Engineering Education Beyond the Millennium, June 18-21, St. Louis, MO.

17. Craddock, J.N. and Chevalier, L.R., 2000. Web Based Laboratory Manuals in Civil Engineering. International Conference on Engineering Education, Aug. 14-16, Taipei, Taiwan. 
18. Chevalier, L.R., Craddock, J.N, Riley, P.C., and Trunk, B.J., 2000. Interactive Multimedia Labware for Strength of Materials Laboratory. Computer Applications in Engineering Education, 8(1): 31-37.

Biographical Information

DR. LIZETTE CHEVALIER received her B.S. degree in Civil Engineering from Wayne State University, and her M.S. and Ph.D. from Michigan State University. She joined the faculty at Southern Illinois University - Carbondale in 1995. Her main interest is environmental engineering with an emphasis on soil remediation involving nonaqueous phase liquids. In addition she is active in engineering education using modern technology.

DR. JAMES CRADDOCK received his B.S., M.S., and Ph.D. degrees in Aeronautical and Astronautical Engineering from the University of Illinois. He joined the faculty at Southern Illinois University - Carbondale in 1980. His main interest is solid mechanics with an emphasis on composite materials and the finite element method. $\mathrm{He}$ is also active in innovative engineering education using the internet and multimedia.

CHANDRASEKHAR VALLATH is an assistant professor in the Interactive Multimedia Master's Program at Southern Illinois University. He has taught multimedia, advertising, journalism and telecommunications at universities in the U.S. and Singapore and worked in industry as a designer of educational multimedia, systems analyst/programmer, journalist and advertising copywriter.

ALISON ARNDT earned a Bachelor of Arts degree in Mass Communication with an emphasis in Television from Idaho State University. Her work experience includes video production for news, public relations, commercial production, and instruction and training. She is currently a graduate student at Southern Illinois University working towards a Master of Arts degree with an emphasis in Interactive Multimedia. 